Journal

of Geography,

Politics and Society

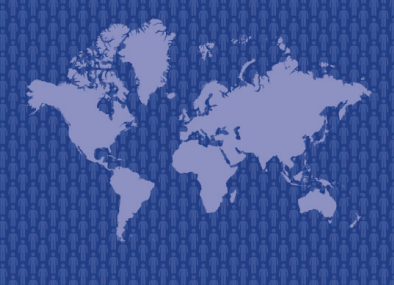

$10(1) / 2020$

\section{Journal of Geography, Politics and Society}

2020, 10(1), 9-14

https://doi.org/10.26881/jpgs.2020.1.02

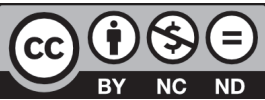

\title{
A PATTERN OF ALCOHOL CONSUMPTION AMONG MARIJUANA USERS IN THE ADULT POPULATION OF THE CITY OF GDAŃSK
}

\author{
Maciej Brosz \\ Institute of Sociology, University of Gdańsk, Bażyńskiego 4, 80-309 Gdańsk, Poland, ORCID: 0000-0002-9621-5588 \\ e-mail: maciej.brosz@ug.edu.pl
}

\section{Citation}

Brosz M., 2020, A pattern of alcohol consumption among marijuana users in the adult population of the city of Gdańsk, Journal of Geography, Politics and Society, 10(1), 9-14.

\begin{abstract}
Alcohol and marijuana are the most commonly used psychoactive substances both in Europe and Poland. In the last four years the proportion of marijuana users in the adult population of Gdańsk has almost doubled: from 7.1\% in 2015 to $14.1 \%$ in 2019. The surveys concerning the consumption of alcohol conducted every four years since 2007 indicate a significant fact: the proportion of people who drink is decreasing. However, this does not mean that they drink less or less often. A question elaborated in this article is whether marijuana users consume more or less alcohol than non-users. This article is based on the data collected in a questionnaire survey on alcohol and other psychoactive substance use conducted in Gdańsk in the autumn of 2019 on a representative sample of 1,004 adult residents of the city.
\end{abstract}

Key words

alcohol, marijuana, pattern of consumption, Gdańsk.

\section{Introduction}

Alcohol and marijuana are the most commonly used psychoactive substances in Europe (European..., 2019) and in Poland (Konsumpcja..., 2019). Indicators of the volume of alcohol consumption at the national level show some changes as regards the popularity of its particular types and situations in which they are consumed. Other important changes concern combined use of various substances, such as alcohol and marijuana. The results and observations presented in this article refer to the situation in Gdańsk, a large urban centre in the north of Poland, with a population of nearly half a million $(468,158$ as on 30 June 2019). The case in point is worth observing as the city is dynamically developing: Gdańsk is characterised by growing indicators of perceived quality of life (Załęcki, Brosz, 2017) and a relatively high level of in-migration, stemming from prosperity in the labour market.

Addressing the issue in focus has been motivated by the fact that in the last four years the proportion of marijuana users in the adult population of Gdańsk has almost doubled: from 7.1\% in 2015 (Abramowicz et al., 2018a) to $14.1 \%$ in 2019 . This change begs questions about the population of users of 
the drug. Such questions are also important in the context of downplaying the effects of marijuana use and treating it as a drug which is safe (Popova et al., 2017, Okaneku et al., 2015) and has less dangerous social effects than alcohol (Rezkalla, Kloner, 2014; Simmons, Carey, 2002).

Patterns of psychoactive substance use are changing. Regular surveys concerning the consumption of alcohol conducted every four years since 2007 indicate a significant fact: the proportion of people who drink is decreasing. However, this does not mean that they drink less or less often. In an attempt to answer a general question whether marijuana users consume more or less alcohol than non-users, this article sets out to achieve the following objectives:

(1) to identify a pattern of alcohol consumption among marijuana users in a large urban centre on the example of the adult population of Gdańsk, taking into account a substantial increase in the user population in the last four years. In other words: what changes have occurred in the population of Gdańsk in terms of the widespread use of marijuana and its frequency?

(2) to compare the patterns of alcohol consumption among marijuana users and non-users; identified differences will serve as a point of departure for in-depth studies on combined use of the two substances;

(3) to investigate the socio-demographic profile of marijuana users in a large urban centre: Who are they? What are the social characteristics of this group of psychoactive substance users? Has their population changed over the last four years?

The collected data did not make it possible to identify and study those who engage in simultaneous alcohol and marijuana (SAM) use, which brings much more significant negative effects than marijuana or alcohol use separately (Lee et al., 2017). The survey conducted in Gdańsk clearly indicates that alcohol consumption among marijuana users displays a pattern whereby they drink more often and more heavily than non-users. It can be assumed that this category includes SAM users.

\section{Methodology}

This article is based on the data collected in a questionnaire survey on alcohol and other psychoactive substance use conducted in Gdańsk in the autumn of 2019 on a representative sample of 1,004 adult residents of the city $(n=1004)$. It should be stressed that the selection of the sample was not guided by any factors related to the issue in focus of the study, i.e. the use of psychoactive substances (alcohol, marijuana, over-the-counter painkillers and so on).

The representativeness of the sample was achieved by (1) reflecting the basic demographic characteristics of Gdańsk population (sex, age) and their territorial distribution (city districts), (2) random selection of particular individuals for the study. First, households were selected using the random route method; next, a member of each household who answered the age and sex criteria was selected using simple random sampling. According to the adopted procedure, only one member of a household could be surveyed. Considering the sensitive nature of the issues in focus, the respondents were given the questionnaires and completed them in their own time; they were collected at a later date.

The questionnaire used in the study was highly standardised and included 46 questions in total: 30 closed questions, 1 open question, 6 scale questions, 9 demographics questions. Issues concerning alcohol and marijuana use were addressed in 11 questions about: the fact of using a particular substance/ type of substance (beer, wine/sparkling wine, vod$\mathrm{ka} /$ other spirits, marijuana) in the preceding 12 months (possible replies: Yes/No); the frequency of its use (possible replies: 5 or more times a week, 3-4 times a week, once or twice a week, once a month, 6 or more times in the last 12 months, up to 5 times in the last 12 months); in the case of alcohol: the amount usually consumed on one occasion, measured in - beer: pints (kufel, about 0.5 litre), wine/ sparkling wine: $100 \mathrm{ml}$ glasses, vodka/other spirits: $50 \mathrm{ml}$ glasses.

Data processing and analysis involved data aggregation based on questions about the use of marijuana and particular types of alcohol, and testing the statistical significance of correlations between particular variables using chi-square test and logistic regression. For the purpose of analysis presented in this article, the applied data indexing procedures concerned not only the fact but also the frequency and volume of alcohol consumption. This made it possible to develop measures of drinking alcohol frequently and in large quantities. As applied here, consumption of a large amount of alcohol on one occasion means drinking at least three pints of beer or $100 \mathrm{ml}$ glasses of wine or $50 \mathrm{ml}$ glasses of highpercentage beverages, and high frequency - drinking at least once or twice a week. Data processing and statistical analysis were performed using $\mathrm{R}$ (3.6.2) and RStudio (1.2.5033) software. 


\section{Results}

$14.1 \%$ of the surveyed adult residents of Gdańsk admitted using marijuana in the 12 months preceding the study. This result is almost twice as high as that recorded in $2015-7.1 \%$ (Abramowicz et al., 2018b). Compared to the study conducted in 2015, the frequency of marijuana use was also higher: the proportion of those who used it at least 5-6 times a week increased from $6.8 \%$ to $13.0 \%$, and up to 4 times a week - from $5.1 \%$ to as much as $36.7 \%$.

The recorded proportion of those who drank alcohol was higher among marijuana users than nonusers - the former admitted drinking beer in the 12 months preceding the study more often than the latter: $83.1 \%$ vs $68.6 \%\left(x^{2}=12.726, d f=1, p=0.001\right)$; the corresponding figures for wine were $66.9 \%$ and $55.0 \%\left(X^{2}=6.570, d f=1, p=0.01\right)$, and for vodka/ other spirits $-73.2 \%$ and $50.0 \%\left(x^{2}=25.526, d f=1\right.$, $p=0.000$ ) (see fig. 1). Compared to non-users, then, the proportion recorded for users was significantly higher in the case of each type of alcohol. More indepth information was provided by measures taking into account the frequency of use of a given type of substance and, in the case of alcohol, the volume of consumption.

Considering the frequency of alcohol consumption, it is apparent that it was higher among marijuana users than other respondents. An index developed to measure it was based on the following replies to questions about the frequency of consumption of particular types of alcohol: " 5 or more times a week", "3-4 times a week", "once or twice a week". The proportion of frequent drinkers among non-users of marijuana was $28.4 \%$, and among users $-49.4 \%\left(x^{2}=23.711, d f=1, p<0.001\right)$.

The analysis also included another parameter: the volume of alcohol consumption on one occasion. This makes it possible to answer the question whether marijuana users drank more or less than non-users. Based on an indexed measure of the volume of consumption on one occasion (at least three pints of beer, $100 \mathrm{ml}$ glasses of wine or $50 \mathrm{ml}$ glasses of vodka/other spirits), it turns out that respondents who admitted using marijuana in the 12 months preceding the study drank more than those who did not use this drug. In the case of marijuana users, the proportion of replies indicating consumption of a large amount of alcohol on one occasion was much higher than among non-users: the respective figures were $50.0 \%$ and $18.4 \%\left(X^{2}=66.961, d f=1\right.$, $p<0.001$ ) (see fig. 2).

An index including both the frequency and the volume of alcohol consumption revealed statistically significant correlation between marijuana use and drinking beer or vodka; no such correlation was recorded in the case of wine. Respondents who were marijuana users were high-frequency consumers of large quantities of beer more often than nonusers: the respective figures were $21.1 \%$ and $5.8 \%$

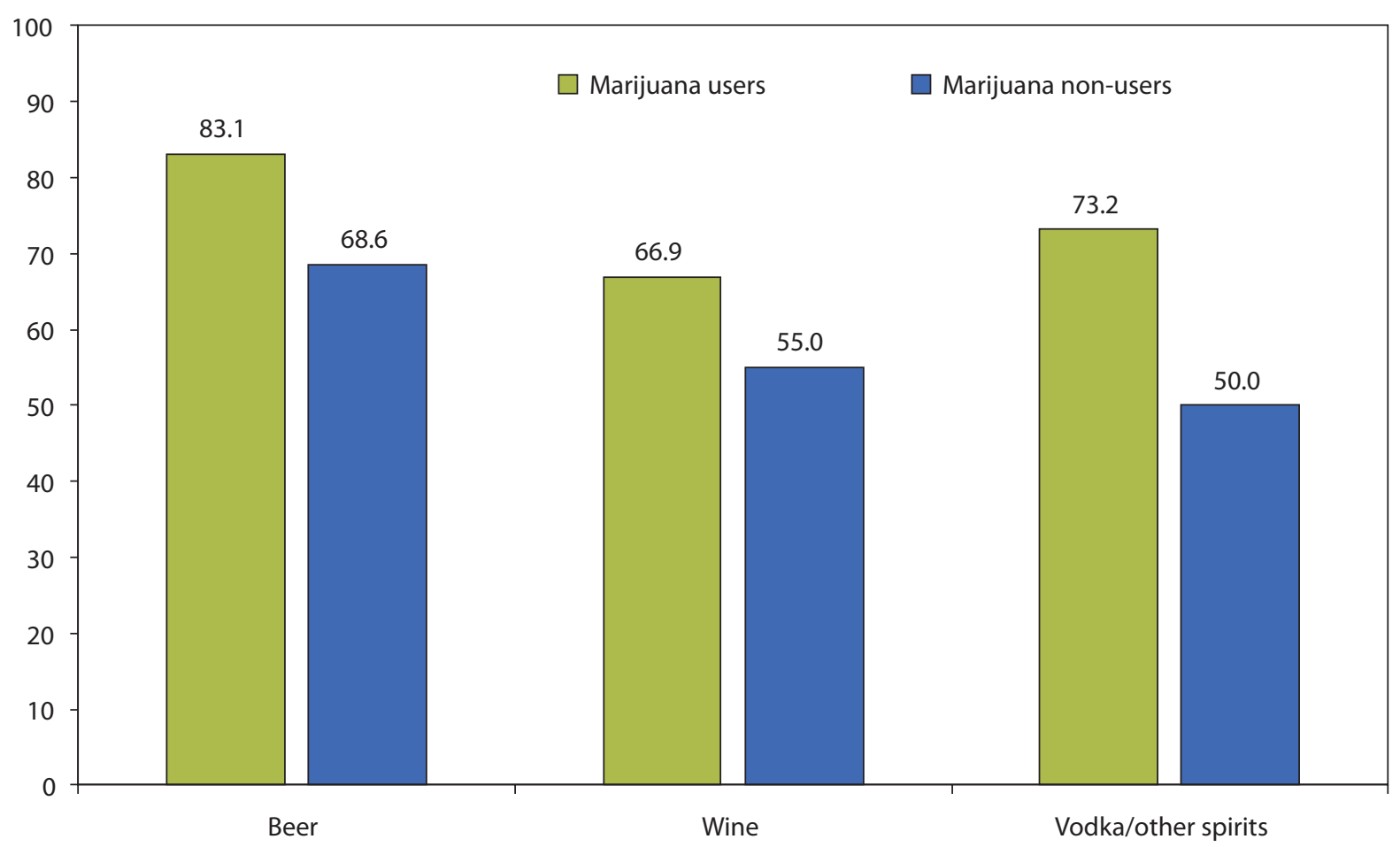

Fig. 1. Consumption of alcohol (beer, wine, vodka) among marijuana users and non-users (\%)

Source: The author's own study. 


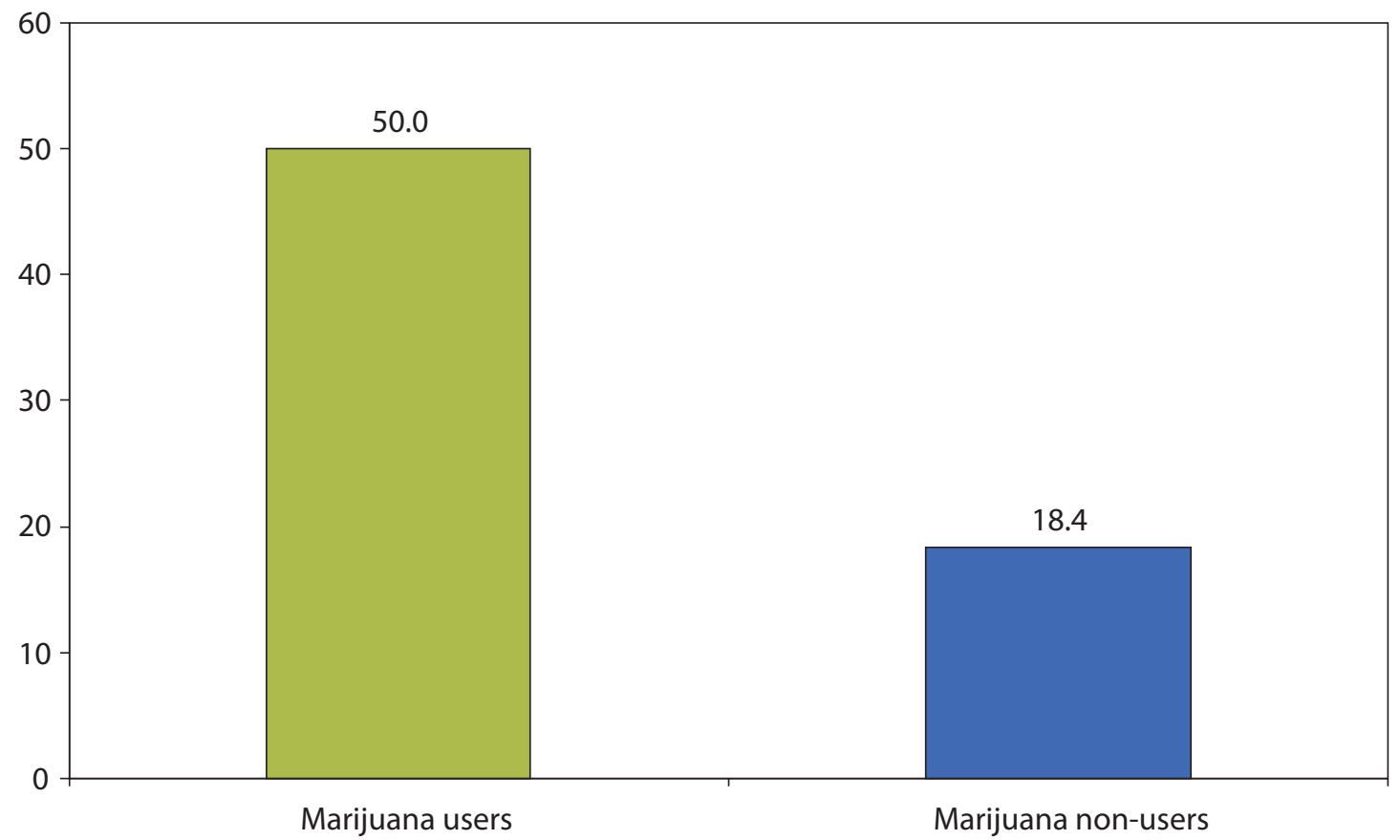

Fig. 2. Consumption of a large amount of alcohol on one occasion among marijuana users and non-users (\%) Source: The author's own study.

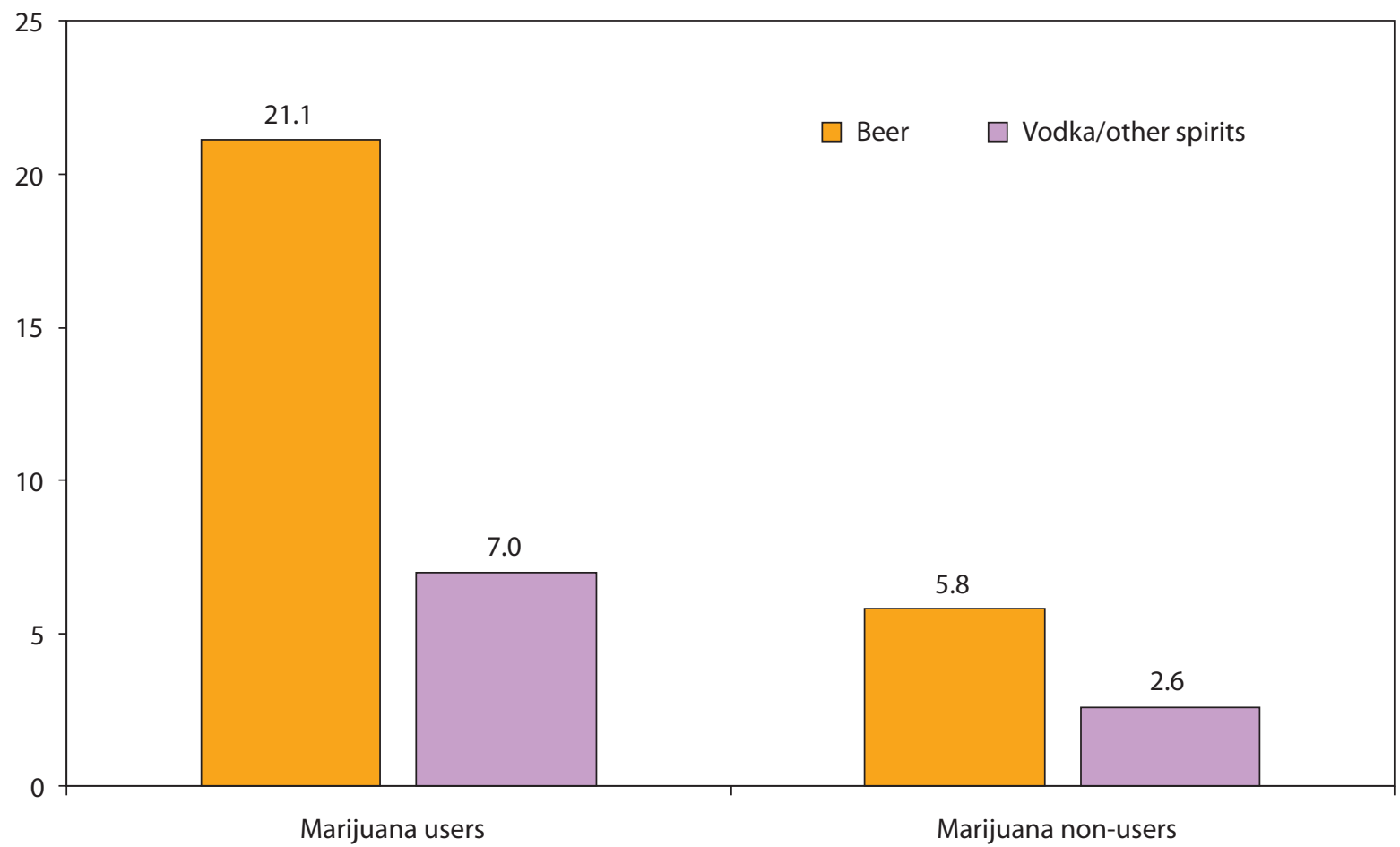

Fig. 3. High-frequency consumption of alcohol (beer, vodka/other spirits) in large quantities among marijuana users and non-users (\%)

Source: The author's own study.

$\left(X^{2}=36.990, d f=1, p<0.001\right)$. The pattern was the same in the case of vodka/other spirits: $7.0 \%$ and $2.6 \%\left(x^{2}=6.577, d f=1, p<0.01\right)$ (see fig. 3 ).

What was the profile of marijuana users? Most of them were male $(18.7 \%)$ rather than female $(10.2 \%)$ $\left(X^{2}=13.984, d f=1, p<0.01\right)$, belonged to the youngest age group of the respondents: 18-29 years old $(37.3 \%)\left(x^{2}=92.942, d f=4, p<0.01\right)$, and were in education (36.4\%) $\left(x^{2}=28.846, d f=3, p<0.01\right)$; they were mostly unmarried $(30.8 \%)\left(x^{2}=52.209\right.$, $\mathrm{df}=3, \mathrm{p}<0.01)$, non-believers and non-practitioners $(34.5 \%)\left(x^{2}=42.905, d f=4, p<0.01\right)$. Other variables 
considered in the study - such as the level of education, income, the fact of having children and their number in the household, a sense of satisfaction with life - did not have a significant impact on replies to the question concerning the use of marijuana.

\section{Discussion}

The group of marijuana users among the adult population of Gdańsk has doubled over the last four years. At the time when the study discussed here was conducted (autumn 2019), one in seven adult residents of the city could be considered a user of the substance. What also increased was the frequency of marijuana use: one in seven users used it almost every day. This observation cannot be left without a comment. It also begs the question concerning the consumption of alcohol among marijuana users. Considering the demographics (presented above) such as age, work situation and marital status, it can be assumed that what plays the key role here is social factors related to group membership, to seeking support, and to prevailing patterns of reference. Single young people who are in education search for their place, try to fulfil their aspirations and to achieve and maintain a certain social status.

The observed increase in indicators reflecting the scale of marijuana use may be related to the media image of the drug - to how it is presented in films, music and the Internet - which young people and young adults refer to when they develop their cognitive habits and their ideas. The issue of users' awareness of negative effects of the drug is an interesting study question in its own right, particularly in the context of common-sense opinions echoed by the young generation, according to which marijuana is a safe alternative to alcohol and other drugs. This view tends to be supported by invoking the medicinal use of marijuana.

In the case of the adult population of Gdańsk, more marijuana users than non-users drink alcohol (all types); they also drink more often and more heavily. In the former category of respondents, the proportion of those who admitted drinking beer, wine or vodka/other sprits in the 12 months preceding the study was higher (the difference was well over ten percentage points). The results of the study clearly indicate that not only the fact of consumption as such but, most importantly, also its frequency and volume display a similar pattern. Marijuana users drink far more often than non-users: the applied index of frequent consumption (at least once or twice a week) showed a difference of 21 percentage points between the two groups. They also drink more heavily - according to the applied index of high-volume consumption the difference is quite considerable: while every second marijuana user has at least three measures of a particular type of alcohol on one occasion, the corresponding proportion for non-users is less than one in five. An analysis considering both the frequency and the volume of alcohol consumption suggests that marijuana users drink beer or vodka more often and in larger amounts than other respondents; no such correlation was recorded in the case of wine. As it turns out, the pattern of alcohol consumption among marijuana users is that they drink more often and more heavily; marijuana use can be identified as a risk factor for increasing it.

A comparison between survey results presented here and those recorded in 2015 (Abramowicz et al., 2018b) indicates that the population of marijuana users has not significantly changed in terms of its demographic profile: it is still mainly composed of single young males in education who are non-believers and non-practitioners. However, it is important to note that one factor included in both surveys has undergone an interesting change. While in 2015 marijuana was more often used by respondents dissatisfied with their lives, in 2019 this factor did not have a significant impact on the distribution of replies - the drug was used not only by those who could be characterised as sensation seekers or people who want to raise their spirits (Linden-Carmichael et al., 2019; Zuckerman, 2007). The fact that marijuana use is no longer correlated with the subjective sense of satisfaction with one's life prompts a conclusion that the drug is becoming more popular. In other words, the use of marijuana is subject to peculiar democratisation. Since the issue of reasons for this state of affairs is beyond the scope of this article, it will be addressed in another study.

It is also worth noting other limitations of this discussion as well as plans for further research. Presumably, activities increasing access to marijuana (e.g. medical use) on the one hand, and the absence of intensified information campaign on the negative effects of its use on the other, foster the perception of the drug as an "equivalent of alcohol", particularly among users and potential users. However, this assumption has not been verified in this article. Consultations with practitioners and specialists in addiction prevention and substance-related harm reduction conducted as part of this project made it possible to formulate the following study question: If the proportion of alcohol users is decreasing, does it mean that they use something else instead? (Abramowicz et al., 2018a; Abramowicz et al., 2018b). Providing an answer to this question will increase our knowledge 
about the nature of changes in patterns of psychoactive substance use.

As mentioned in the introduction, the growing proportion of marijuana users on the one hand, and specific patterns of alcohol consumption in this population on the other, indicate the likelihood of emerging a group using both substances simultaneously. Verifying this assumption requires analysing their practices in the context of SAM use characteristics documented in the literature on the subject. As planned, this task will be part of further studies among adult residents of the city of Gdańsk.

\section{References}

Abramowicz M., Brosz M., Bykowska-Godlewska B., Michalski T., Strzałkowska A., 2018a, Narkotyki, alkohol i dopalacze. Diagnoza problemu. Studium socjologiczne na podstawie badań wśród mieszkańców Gdańska (Eng. Drugs, alcohol and designer drugs: A diagnosis of the problem. A sociological study based on a survey among residents of the city of Gdańsk), Wydawnictwo Zakładu Realizacji Badań Społecznych Q\&Q, Kawle Dolne.

Abramowicz M., Brosz M., Bykowska-Godlewska B., Michalski T., Strzałkowska A., 2018b, Wzorce konsumpcji alkoholu: studium socjologiczne (Eng. Patterns of alcohol consumption: A sociological study), Wydawnictwo Zakładu Realizacji Badań Społecznych Q\&Q, Kawle Dolne.

European Drug Report: Trends and Developments, 2019, European Monitoring Centre for Drugs and Drug Addiction, Luxembourg. doi: 10.2810/191370

Konsumpcja alkoholu w Polsce (Eng. Alcohol consumption in Poland), 2019, Komunikat z badań Centrum Badań Opinii Społecznej (Eng. A survey report by the Public Opinion Research Center), 151/2019.

Lee C.M., Cadigan J.M., Patrick M.E., 2017, Differences in reporting of perceived acute effects of alcohol use, marijuana use, and simultaneous alcohol and marijuana use, Drug and Alcohol Dependence, 180, 391-394. doi: 10.1016/j.drugalcdep.2017.08.029

Linden-Carmichael A.N., Stamates A.L., Lau-Barraco C., 2019, Simultaneous use of alcohol and marijuana: Patterns and individual differences, Substance Use \& Misuse, 54(13), 2156-2166. doi: 10.1080/10826084.2019.1638407

Okaneku J., Vearrier D., McKeever R.G., LaSala G.S., Greenberg M.I., 2015, Change in perceived risk associated with marijuana use in the United States from 2002 to 2012, Clinical Toxicology, 53(3), 151-155. doi: 10.3109/15563650.2015.1004581

Popova L., McDonald E.A., Sidhu S., Barry R., Richers Maruyama T.A., Sheon N.M., Ling P.M., 2017, Perceived harms and benefits of tobacco, marijuana, and electronic vaporizers among young adults in Colorado: Implications for health education and research, Addiction, 112(10), 1821-1829. doi: 10.1111/add.13854
Rezkalla S., Kloner R. A., 2014, Recreational marijuana use: Is it safe for your patient?, Journal of the American Heart Association, 3(2), 1-3. doi: 10.1161/JAHA.114.00090

Simons J.S., Carey K.B., 2002, Risk and vulnerability for marijuana use problems: The role of affect dysregulation, Psychology of Addictive Behaviors, 16(1), 72-75. doi: 10.1037/0893-164X.16.1.72

Załęcki J., Brosz M., 2017, Jakośćżycia w Gdańskuijej społecznoprzestrzenne uwarunkowania. Studium socjologiczne (Eng. The quality of life in the city of Gdańsk and its sociospatial conditions: A sociological study), Wydawnictwo Zakładu Realizacji Badań Społecznych Q\&Q, Kawle Dolne. Zuckerman M., 2007, Sensation seeking and risky behavior, American Psychological Association, Washington. 